J. Lake Sci. (湖泊科学) , 2020, 32(1): 207-222

DOI 10. 18307/2020. 0120

(c) 2020 by Journal of Lake Sciences

\title{
1960-2012 年鄱阳湖流域旱涝急转事件时空演变特征
}

\author{
王 容 $^{1,2}$, 李相虎 ${ }^{1,2 * *}$, 薛晨阳 ${ }^{1,2}, 弓^{2}$ 丹 $^{1}$ \\ (1: 中国科学院南京地理与湖泊研究所,中国科学院流域地理学重点实验室,南京 210008) \\ (2: 中国科学院大学, 北京 100049)
}

\begin{abstract}
摘 要: 基于鄱阳湖流域五河 7 个主要人湖控制站 1960-2012 年的实测径流资料, 通过短周期旱涝急转指数, 结合 TFPWMK 趋势检验法及集合经验模态分解法,分析了鄱阳湖流域旱涝急转事件的时空分布、演变趋势、强度及周期变化等, 并探讨 了旱涝急转指数的不确定性及旱涝急转事件的成因. 结果表明: 鄱阳湖流域旱涝急转事件主要分布在 3-10月, 其中 3-6 月主要表现为“旱转涝”, 7-10 月主要表现为“涝转旱”, 且不同年代间存在一定的时空差异; 五河以轻度旱涝急转事件为 主, 重度旱涝急转事件发生频率较低, 主要发生在抚河、信江和饶河流域, 且多以“涝转旱”事件为主; 在年代际上,鄱阳湖流 域旱涝急转事件在 $1990 \mathrm{~s}$ 发生的频率最高, 在 2000s 最低. 同时, 除饶河外, 鄱阳湖流域年最强“涝转旱”事件的发生强度呈减 弱趋势, 而年最强“旱转涝”事件的发生强度在赣江和修水北支有减弱趋势, 在饶河和修水南支有增强趋势. 五河旱涝急转的 变化存在 2 个特征时间尺度,分别为 $1 \mathrm{a}$ 和 $21 \sim 35 \mathrm{a}$, 而年最强旱涝急转事件的发生强度具有 $3 \mathrm{a}$ 左右的周期变化特征. 这些 变化与流域降水的不均匀性及强烈的人类活动等有关. 本研究结果有助于全面系统认识鄱阳湖流域在全球变暖背景下极端 水文事件的发生机制和变化规律,可为鄱阳湖区防汛抗旱减灾提供重要的科学依据.
\end{abstract}

关键词: 鄱阳湖流域; 径流; 旱涝急转;时空分布;周期

\section{Spatio-temporal variations of the drought-flood abrupt alternation events in the Lake Poy- ang Basin from 1960 to $2012^{*}$}

\author{
WANG Rong ${ }^{1,2}$, LI Xianghu ${ }^{1,2 * *}$, XUE Chenyang ${ }^{1,2} \&$ ZHANG Dan ${ }^{1}$ \\ (1: Key Laboratory of Watershed Geographic Sciences, Nanjing Institute of Geography and Limnology, Chinese Academy of \\ Sciences, Nanjing 210008,P.R. China) \\ (2: University of Chinese Academy of Sciences, Beijing 100049, P.R.China)
}

\begin{abstract}
Based on the observed daily runoff data from 7 hydrological stations covering 1960 to 2012 in the Lake Poyang Basin, this study identified and analyzed the spatiotemporal variations of the drought-flood abrupt alternation events (DFAAE) by applying the short drought-flood abrupt alternation index (SDFI), TFPW-MK trend test and Ensemble Empirical Mode Decomposition (EEMD). Further, the uncertainty of SDFI and the causes of DFAAE were also explored. The results revealed that DFAAE in Lake Poyang Basin generally occurred during March and October. Among these, the drought-to-flood events of Lake Poyang Basin mainly occurred during March and June, while the flood-to-drought events mainly occurred during July and October, with spatiotemporal difference existed between different ages. Mild DFAAE was the dominated events in the Lake Poyang Basin, while extreme DFAAE occurred less frequently. The extreme DFAAE was mainly concentrated in Fuhe River, Xinjiang River, and Raohe River sub-basins. Most of them were flood-to-drought events. The occurrence frequency of DFAAE was the highest in the 1990s and the lowest in 2000s. The TFPW-MK trend test of the minimum and maximum values of SDFI indicated there was a long-term decreasing trend in the intensity of the strongest flood-to-drought events of in the catchment except for Raohe River. Meanwhile, a decreasing trend for the occurrence intensity of the strongest drought-to-flood events was also found in Ganjiang River and the northern Xiushui River Basins. Relatively, an increasing trend occurred in Raihe River and the southern Xiushui River Basins. SDFI in the Lake Poyang Basin had two cycles which were 1 year and 21-35 years. In addition, there was a 3-year cycle in the occurrence intensity of the
\end{abstract}

* 2019-03-12 收稿;2019-06-27 收修改稿.

中国科学院 A 类战略性先导科技专项 (XDA23040202) 和国家自然科学基金项目 (41571023,41871093) 联合资助.

** 通信作者;E-mail:xhli@ niglas.ac.cn. 
strongest DFAAE. The temporal and spatial variations of DFAAE were affected by spatial heterogeneity of precipitation and the strong human activities, etc. This study facilitates us to further understand the mechanism and change patterns of the extreme drought and flood events in the Lake Poyang Basin under the background of climate change. It also provides an important scientific basis for flood control, drought relief and disaster reduction in the Lake Poyang Basin.

Keywords: Lake Poyang Basin; runoff; drought-flood abrupt alternation; spatiotemporal patterns; cycle

当前由于全球气候变暖、城市化进程加快使得水循环速率加快、系统稳定性降低, 导致干旱、洪涝等极端 水文事件发生的频率和强度不断增加, 对生态系统和人类社会发展造成严重的危害 ${ }^{[1-3]}$. 与此同时, 旱涝急转 现象也在不断增加 ${ }^{[4-5]}$, 尤其在我国华南、西南、长江中下游及淮河流域等地区表现得更加明显 ${ }^{[6-7]}$, 已成为我 国旱涝灾害的一种新特点与新趋势 ${ }^{[8]}$. 例如, 广西在 2005 年、 2009 年及 2013 年多次出现旱涝急转现象 ${ }^{[9]}$, 在 珠江的东江流域、淮河流域也曾多次发生 ${ }^{[10-11]}$, 而在 2011 年春夏之交, 我国长江中下游地区发生的一次快速、 剧烈的旱涝急转现象, 其旱涝转变之快、旱涝灾情之重、影响范围之广, 更是近年来罕见 ${ }^{[12]}$, 给我国经济发展和 人民的财产带来巨大的损失. 旱涝急转是旱涝并存现象的一种极端表现 ${ }^{[13]}$, 不仅具备干旱和洪涝分别具有的 灾害特性, 其所造成的危害比单一灾害的叠加更为严重 ${ }^{[14-16]}$. 因此, 对区域旱涝急转现象的研究已引起国内外 学者的广泛关注, 其演变规律与影响研究也是水文与气候变化研究领域呕待解决的一个科学问题.

近些年来, 诸多学者利用不同的指标与方法对旱涝急转现象进行了研究, 成果颇丰, 也为揭示旱涝急转 的时空特征及其成因机制等提供了很好的基础. 例如, 吴志伟等 ${ }^{[6]}$ 通过对比夏季降水差异定义了降水长周 期旱涝急转指数, 用于定量研究长江中下游地区旱涝急转现象. 程智等 ${ }^{[17]}$ 在挑选出淮河流域旱涝急转事件 的基础上,定义了一个基于 SPI 指数的旱涝急转事件强度指数,并进一步分析了其时空分布和强度差异变 化. 熊威等 ${ }^{[18]}$ 基于游程理论分析了四湖流域旱涝急转事件的历时、强度和程度,并通过 Copula 函数构建了 旱涝急转事件特征变量间的联合分布, 分析了相应的概率和重现期. 唐明等 ${ }^{[19]}$ 从时间和空间两方面对淮北 地区旱涝急转现象进行了定量描述, 并简要分析了旱涝急转的成因. 张屏等 ${ }^{[15]}$ 利用一组经验降水阈值指数 定义了一个针对安徽省淮北地区的旱涝急转指数, 并分析了其季节演变特征. 闪丽洁等 ${ }^{[8]}$ 在原有长周期旱 涝急转指数基础上定义了日尺度旱涝急转指数, 并基于此分析了长江中下游地区夏季旱涝急转事件的时空 特征及其与 ENSO 的关系. 另外, 张水锋等 ${ }^{[1]} 、$ 罗蔚等 ${ }^{[20]} 、 \mathrm{Li}$ 等 ${ }^{[21]}$ 还从径流量异常变化的角度研究了淮河流 域、鄱阳湖流域旱涝急转现象的发生规律.

鄱阳湖是我国第一大淡水湖,也是我国重要的战略水源地, 其独特的湿地生态系统, 具有极其丰富的湿 地植被资源与物种多样性, 发挥着巨大的生态服务功能 ${ }^{[22-23]}$, 同时鄱阳湖流域还是我国重要的商品粮基地. 然而由于鄱阳湖区域河一湖关系复杂, 历来是我国洪旱灾害最严重的区域之一 ${ }^{[24]}$. 近些年来, 在气候变化与 人类活动的双重影响下, 鄱阳湖流域极端干旱事件频发、季节性水资源紧张、湖泊面积萎缩、湖泊水质趋于 恶化、水域和湿地生态系统结构与功能退化,给鄱阳湖流域水安全和生态系统平衡等带来了巨大威胁 ${ }^{[25-31]}$. 以往研究多侧重于该区域单一干旱或洪涝, 而对旱涝急转这种复合型灾害现象关注较少. 目前有关于鄱阳 湖流域旱涝急转的研究重点分析了旱涝急转的变化趋势, 未对旱涝急转的发生强度及周期变化等方面进行 特征分析, 且对旱涝急转的空间差异及其成因等都还不清晰 ${ }^{[20-21]}$. 因此本文侧重于研究鄱阳湖流域旱涝急 转事件的空间差异、强度及周期变化等, 并讨论旱涝急转指数的不确定性及旱涝急转事件的成因. 本研究对 进一步认识鄱阳湖洪旱灾害的发生机理、保障湖泊水安全与生态安全具有重要意义,同时可为鄱阳湖区防 汛抗旱减灾、生态环境保护、制定流域综合管理措施等提供科学依据.

\section{1 研究区域与方法}

\section{1 研究区域与数据资料}

鄱阳湖流域 (图 1) 位于长江中下游地区, 流域面积 $16.22 \times 10^{4} \mathrm{~km}^{2}$, 约占长江流域面积的 $9 \%$, 流域内水 系发达, 主要有修水、赣江、抚河、信江、饶河五大支流,其地貌类型主要包括山地、丘陵和岗地平原 3 类 ${ }^{[32-33]}$. 鄱阳湖流域地处亚热带季风区, 气候温暖, 降水丰沛, 年平均气温为 $18^{\circ} \mathrm{C}, 1960-2012$ 年平均年降水量为 $1676 \mathrm{~mm}$, 鄱阳湖流域降水年内分布呈现出显著的季节性差异, 一般从 4 月开始进人雨季, 5-6 月降水量达 
全年最高值, 期间径流量迅速增加, 雨季径流量约占全年径流量的 50\%; 从 7 月开始, 降水量急剧减小, 在 9 月之后, 鄱阳湖流域开始进人旱季并且持续到 12 月 ${ }^{[21,26]}$.

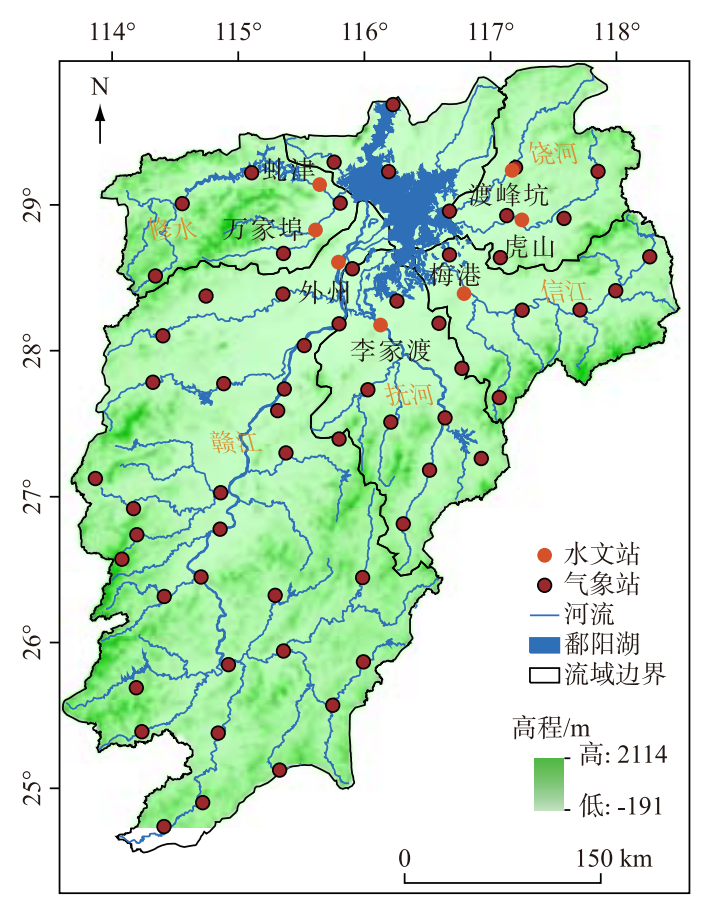

图 1 鄱阳湖流域地理位置及主要站点分布

Fig.1 Location of the study area and the distribution of stations in Lake Poyang Basin

研究中, 鄱阳湖流域 1960-2012 年五河 7 个主要人湖控制站 (表 1) 逐日径流观测数据来源于长江水利 委员会水文局,主要用于对鄱阳湖流域旱涝急转事件的识别及其时空演变特征分析. 流域内 61 个雨量站同 时期的降水数据来源于国家气象信息中心, 主要用于对旱涝急转事件成因分析.

表 1 鄱阳湖流域五河 7 个人湖控制站

Tab. 1 List of 7 stations in Lake Poyang Basin

\begin{tabular}{cccccc}
\hline \multirow{2}{*}{ 序号 } & 河流 & 径流控制站 & \multicolumn{2}{c}{ 坐标 } & \multirow{2}{*}{ 控制面积 $/ \mathrm{km}^{2}$} \\
\cline { 4 - 5 } & & 北纬 ${ }^{\circ}$ & 28.38 & 80948 \\
2 & 赣江 & 外州 & 115.50 & 28.13 & 15811 \\
3 & 抚河 & 李家渡 & 116.10 & 28.26 & 15535 \\
4 & 信江 & 梅港 & 116.49 & 29.16 & 5013 \\
5 & 饶河北支 & 渡峰坑 & 117.12 & 28.55 & 6374 \\
6 & 饶河南支 & 虎山 & 117.16 & 29.10 & 9914 \\
7 & 修水北支 & 虬津 & 115.41 & 28.51 & 3548 \\
\hline
\end{tabular}

\section{2 研究方法}

1.2.1 旱涝急转指数 本文基于吴志伟等 ${ }^{[6]}$ 提出的短周期旱涝急转指数 (Short Drought-Flood Abrupt Alternation Index, SDFI), 将其应用于径流, 研究鄱阳湖流域径流旱涝急转事件时空变化. SDFI 可表示为:

$$
S D F I=\left(W_{i+1}-W_{i}\right) \times\left(\left|W_{i+1}\right|+\left|W_{i}\right|\right) \times \alpha^{-\left|W_{i+1}+W_{i}\right|} \quad(i=1,2,3, \cdots, n)
$$

式中, $W_{i}$ 和 $W_{i+1}$ 分别是第 $i$ 月和 $i+1$ 月标准化径流量; $\left(W_{i+1}-W_{i}\right)$ 为旱涝急转强度项; $\left(\left|W_{i+1}\right|+\left|W_{i}\right|\right)$ 为旱涝强度项; $\alpha^{-\left|W_{i+1}+W_{i}\right|}$ 为权重系数, 其中, $\alpha$ 为经验系数, 在研究中取值为 1.5 . 
表 2 鄱阳湖流域旱涝急转等级划分

Tab.2 Categories of the drought-flood abrupt alteration from SDFI in Lake Poyang Basin

\begin{tabular}{ccc}
\hline 序号 & 旱涝急转指数 $(S D F I)$ & 旱涝急转等级 \\
\hline 1 & $>3$ & 重度早转涝 \\
2 & $2 \sim 3$ & 中度早转涝 \\
3 & $1 \sim 2$ & 轻度早转涝 \\
4 & $-1 \sim 1$ & 正常 \\
5 & $-2 \sim-1$ & 轻度涝转早 \\
6 & $-3 \sim-2$ & 中度涝转早 \\
7 & $<-3$ & 重度涝转早 \\
\hline
\end{tabular}

当 $S D F I>0$ 时, 旱涝急转现象表现为 “旱转 涝”, 反之, 当 $S D F I<0$ 时, 则表现为 “涝转早”. 而 $S D F I$ 的绝对值大小, 表示旱涝急转事件的强度大 小. 一般以 $|S D F I|>1$ 作为识别旱涝急转事件的标 准, 绝对值越大, 则旱涝急转的强度越大. 本文综 合考虑旱涝急转事件类型, 借鉴吉中会等划分旱 涝急转的标准 ${ }^{[34]}$, 将鄱阳湖流域早涝急转指数 SDFI 划分为 7 个等级 (表 2):

1.2.2 趋势检验法 本文采用 TFPW-MK 趋势检验 法分析检验序列的变化趋势. TFPW-MK 方法是在 Mann-Kendall 趋势检验的基础上引人了去趋势预 置白法 (TFPW), 可有效降低序列中自相关对结

果的影响. TFPW-MK 法先进行趋势项成分提取再进行预置白处理,这可有效避免预置白处理对序列趋势程 度的改变 ${ }^{[35-36]}$. 具体计算步骤如下:

1) 计算检验时间序列 $Y(t)(t=1,2, \cdots, n)$ 的倾斜度 $\gamma$ :

$$
\gamma=\operatorname{median} \frac{\left(y_{k}-y_{m}\right)}{k-m} \quad(\forall k>m)
$$

式中, $y_{m}$ 和 $y_{k}$ 为待检序列样本值, $n$ 为序列长度 $(m, k=1,2, \cdots, n)$.

2) 计算去除趋势项序列的一阶自相关系数 $r_{1}$. 去除趋势项序列 $Y_{1}(t)=Y(t)-\gamma t$.

$$
r_{1}=\frac{\sum_{m=1}^{n-1}\left(y_{m}-\bar{y}_{m}\right)\left(y_{m+1}-\bar{y}_{m+1}\right)}{\sqrt{\sum_{m=1}^{n-1}\left(y_{m}-\bar{y}_{m}\right)^{2} \sum_{m=1}^{n-1}\left(y_{m+1}-\bar{y}_{m+1}\right)^{2}}}
$$

3 ) 在 $\beta=0.1$ 的显著性水平下 (自由度为 $n-2$ ), 判断 $r_{1}$ 是否达到显著性水平:

$$
r_{\beta}=\frac{1.676}{\sqrt{(n-2)+1.627^{2}}}
$$

当 $\left|r_{1}\right| \geqslant r_{\beta}$ 时,则 $Y_{1}(t)$ 通过显著检验, 反之未通过显著性检验.

$4)$ 对通过显著性检验的序列 $Y_{1}(t)$ 进行去除自相关项处理, 形成新序列 $Y_{2}(t)=Y_{1}(t)-r_{1} Y_{1}(t-1)$, 加 原趋势项后形成去除自相关性影响的新序列 $Y_{3}(t), Y_{3}(t)=Y_{2}(t)+\gamma t$.

5 ) 将新形成的序列 $Y_{3}(t)$ 和未通过显著性检验的序列 $Y_{1}(t)$ 进行 MK 趋势检验(显著性水平为 $\alpha=0.05)$.

1.2.3 集合经验模态分解 集合经验模态分解 (Ensemble Empirical Mode Decomposition, EEMD) 是经验模分 解的改进版, 它是一种非线性、非平稳的时间序列分析方法, 基本原理是将研究数据分解成有限个不同时间 尺度的波动信号 ${ }^{[37]}$. 与傅里叶变换和小波变化相比, EEMD 能更加准确地分解出序列的特征波动信号 ${ }^{[38-40]}$. 本文采用 EEMD 方法, 在鄱阳湖流域五河 7 站旱涝急转序列中加人 0.2 倍数据标准差的白噪声, 分解出能反 映不同时间尺度周期变化特征的本征函数 $(I M F)$ 和趋势项 $(S T)$, 通过 0.1 的显著性检验, 获得具有独立代表 性的本征函数, 以作为研究旱涝急转序列的多时间尺度特征的基础.

1.2 .4 降水不均匀系数 本文利用降水年内分配不均匀系数 $\left(C_{v}\right)$ 来衡量降水年内分布的不均匀性 ${ }^{[41]}$. $C_{v}$ 可 表示为:

$$
C_{v}=\sigma / \bar{R}, \bar{R}=\frac{1}{12} \sum_{i=1}^{12} R_{i}, \sigma=\sqrt{\frac{1}{12} \sum_{i=1}^{12}\left(R_{i}-\bar{R}\right)}
$$

式中, $R_{i}$ 为年内各月降水 $(i=1,2,3, \cdots, 12), \bar{R}$ 为年内月平均值. 当降水不均匀系数越大时, 表现为丰枯月 份降水相差越悬殊, 年内分配越不均匀. 


\section{2 结果与分析}

\section{1 鄱阳湖流域旱涝急转事件发生频率的时空变化特征}

鄱阳湖流域五河 7 个径流控制站不同强度旱涝急转事件发生频次的年内分布如图 2 所示. 由图 2 可知, 五河旱涝急转事件在年内分布上具有较好的一致性,旱涝急转主要集中在 3-10月,其中 3-6 月以“旱转
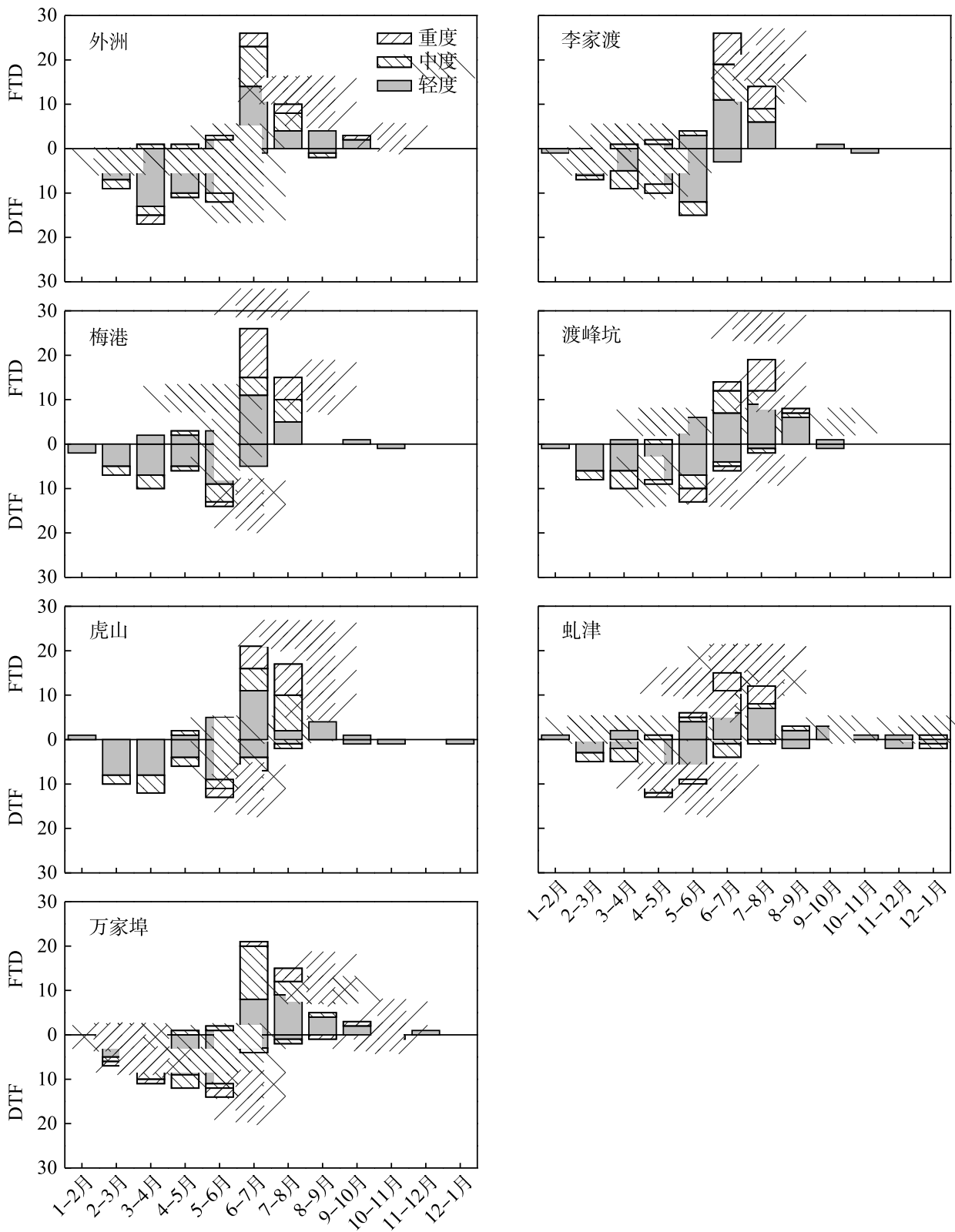

图 2 鄱阳湖流域五河 7 站旱涝急转事件发生频次的年内分布

(FTD 为“涝转旱”事件,DTF 为“旱转涝”事件)

Fig.2 Intra-annual occurrence times of the drought-flood abrupt alteration events at 7 hydrological stations in Lake Poyang Basin( FTD is the flood-to-drought event, and DTF is the drought-to-flood event) 
涝”为主, 7- 10 月以“涝转旱”为主, “旱转涝” 事件与 “涝转旱”事件的发生频次基本相当; 同时, 旱涝急转 事件均以轻度旱涝急转为主, 占总数的 $62.3 \%$, 其次为中度旱涝急转事件, 占总数的 $25.6 \%$, 而重度旱涝急转 事件发生频率较低, 主要集中在 6-8 月, 且多以 “涝转旱”事件为主. 另外发现, 五河之间旱涝急转事件的发 生频次也存在一定的差异, 其中信江的旱涝急转事件发生频次最多, 修水北支最少; 对于重度旱涝急转事 件,则更易发生于抚河、信江和饶河流域,而赣江流域很少出现.

另外, 不同年代间旱涝急转事件在年内分布上存在一定的时空差异 (图 3). 五河 “旱转涝” 事件年内分 布时段普遍较宽,但在部分年代其发生时段较为集中,如抚河 “旱转涝” 事件在 1970s 的 5 月,而在 1990s 和 2000s 则集中在 6 月,信江和饶河南支的“旱转涝”事件在 1990s 的 6 月发生频率最高;五河“涝转旱”事件在 年内分布则相对集中,除赣江 1960s 的“涝转旱”事件集中分布在 6-7 月外,其余年代的“涝转旱” 事件年内 分布和抚河、信江及饶河基本一致,主要分布在 7-8 月,修水则在 1960s、1970s 的 7-8 月分布较集中.

不同年代间鄱阳湖流域五河旱涝急转事件的发生频率如图 4 所示. 由图 4 可知, 2000s 是鄱阳湖流域旱 涝急转事件发生频次最少的年代, 而 1990s 是相对最多的年代. 但五河之间存在较大的差异, 其中赣江和抚 河的旱涝急转事件发生频次自 1960s 呈逐渐减少的趋势, 信江在 1990s 之前也呈逐渐减少的趋势, 而在 1990s 旱涝急转事件大幅增加, 之后又呈减少的趋势, 绕河的旱涝急转事件发生频次在 2000s 以前呈增加趋 势, 但在 2000s 旱涝急转发生频次减少为历史最低, 修水的旱涝急转事件发生频次在不同年代间波动较大, 总体上 1980s 和 2000s 发生频次较低.

\section{2 鄱阳湖流域旱涝急转事件发生强度变化特征}

$S D F I$ 的绝对值大小反映了旱涝急转事件的强度大小, 其年最大值和最小值序列即代表了年最强 “旱转 涝”与“涝转旱” 事件的发生强度, 因此, 以 SDFI 年最值序列分析最强旱涝急转事件强度的年际变化趋势特征 及相应的 TFPW-MK 趋势检验结果 (表 3、图 5). 由图 5 可知,除饶河外, 其余各站 SDFI 最小值均呈上升趋势, 其中外洲、李家渡、虬津及万家埠站更是达到了 0.05 的显著性水平, 表明除饶河外, 鄱阳湖流域年最强 “涝转 旱” 事件发生强度有逐渐减弱的趋势. 而SDFI 最大值序列波动程度不大, 外洲及虬津站呈微弱的下降趋势, 渡 峰坑、虎山和万家埠站呈微弱的上升趋势, 表明赣江和修水北支的年最强“旱转涝” 事件发生强度有减弱趋势, 而饶河和修水南支的年最强“旱转涝”事件发生强度有增强的趋势, 但均未达到 0.05 的显著性水平.

表 3 鄱阳湖流域五河 7 站 SDFI 最小值与最大值序列的趋势检验结果 ${ }^{1)}$

Tab.3 TFPW-MK test trend results about the minimum and maximum series of SDFI at 7 stations in Lake Poyang Basin

\begin{tabular}{cccc}
\hline 序号 & 径流控制站 & TFPW-MK 统计量 SDFI 最小值 & TFPW-MK 统计量 SDFI 最大值 \\
\hline 1 & 外州 & $2.31^{*}$ & -1.45 \\
2 & 李家渡 & $2.28^{*}$ & -0.07 \\
3 & 梅港 & 1.32 & 0.28 \\
4 & 渡峰坑 & -0.02 & 0.56 \\
5 & 虎山 & -0.87 & 0.44 \\
6 & 虬津 & $2.43^{*}$ & -0.48 \\
7 & 万家埠 & $2.41^{*}$ & 1.16 \\
\hline
\end{tabular}

1) TFPW-MK 统计量值为负时表示序列为下降趋势, 反之为上升趋势; $*$ 表示达到了 $\alpha=0.05$ 的显著性水平.

\section{3 鄱阳湖流域旱涝急转事件的周期变化特征}

对鄱阳湖流域五河 7 站 SDFI 序列进行 EEMD 分解,并通过 0.1 的显著性检验得到了 2 个具有独立代表 性的本征函数 (IMF1 及 $I M F 2$ ), 对其进行周期分析 (表 4、图 6). 由图 6 可知, $I M F$ 分量各自反映了 SDFI 序 列中固有的不同时间尺度的振荡特征,各站 $I M F 1$ 的周期均为 $1 \mathrm{a}$, 反映了 SDFI 序列的高频振荡特征. IMF 2 代表了 SDFI 序列中较长时间尺度的周期变化特征, 各支流之间也存在较大差异, 其中李家渡、梅港及虎山 站的振荡周期在 21 26 a 之间, 外州、渡峰坑和虬津站的振荡周期都为 $35 \mathrm{a}$, 而万家埠站的振荡周期最长, $I M F 2$ 达 $53 \mathrm{a}$, 与研究序列长度相同, 为伪周期, 不能真实反映该站的长周期特征. 除万家埠站外, 其余各站 

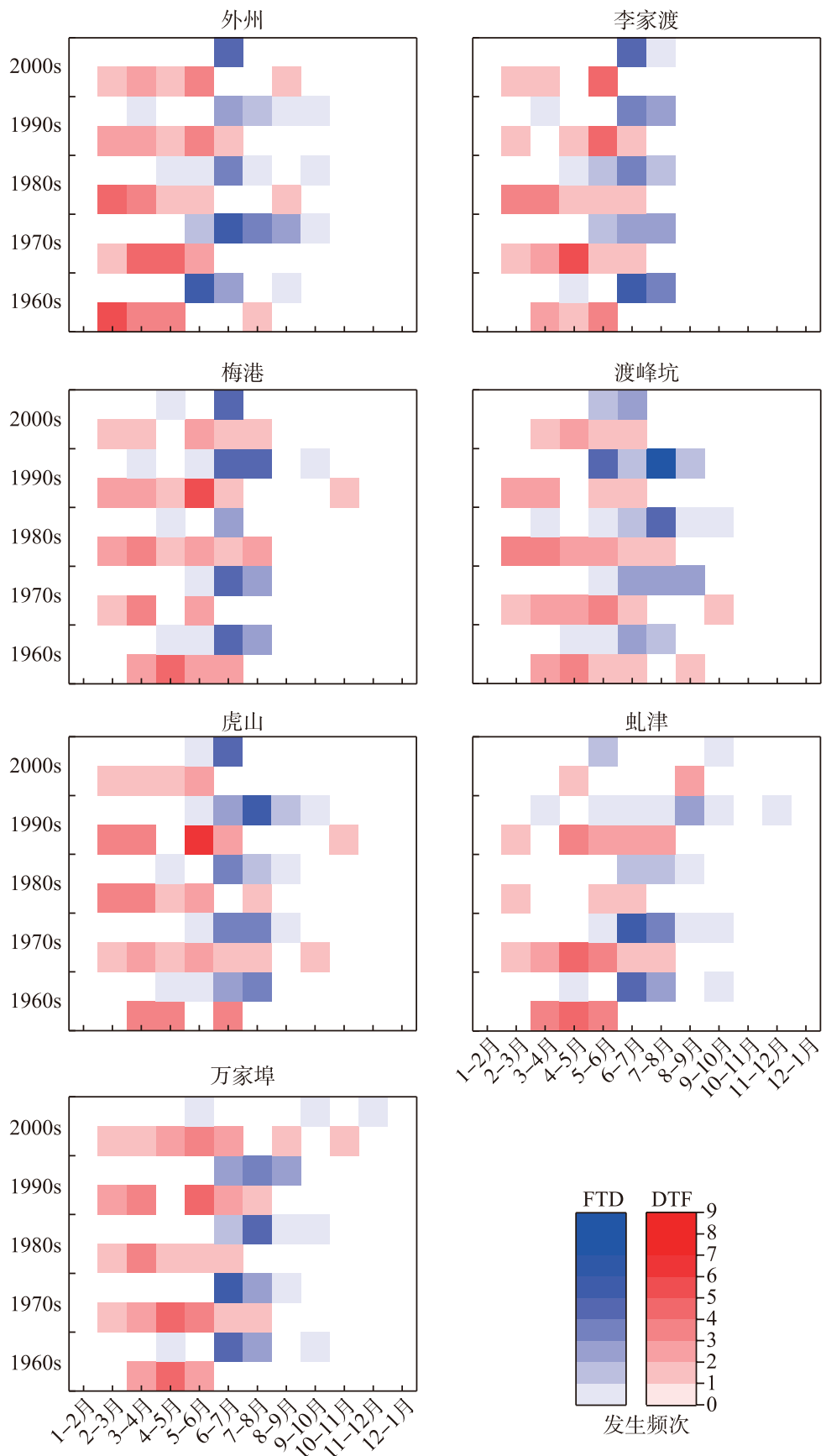

图 3 不同年代鄱阳湖流域五河 7 站旱涝急转事件发生频次的年内分布

Fig.3 Intra-annual occurrence times of the drought-flood abrupt alteration events in different decades at 7 hydrological stations in Lake Poyang Basin

旱涝急转具有 21 35 a 的长周期特征, 这可能与长江中下游地区梅雨的长周期振荡有关 ${ }^{[42-44]}$. EEMD 的趋 势项 $(S T)$ 显示, 渡峰坑和虬津站呈先上升后降低的趋势, 表明渡峰坑和虬津站的 SDFI 在研究时段内有先增 大后减小的趋势,但不明显. 


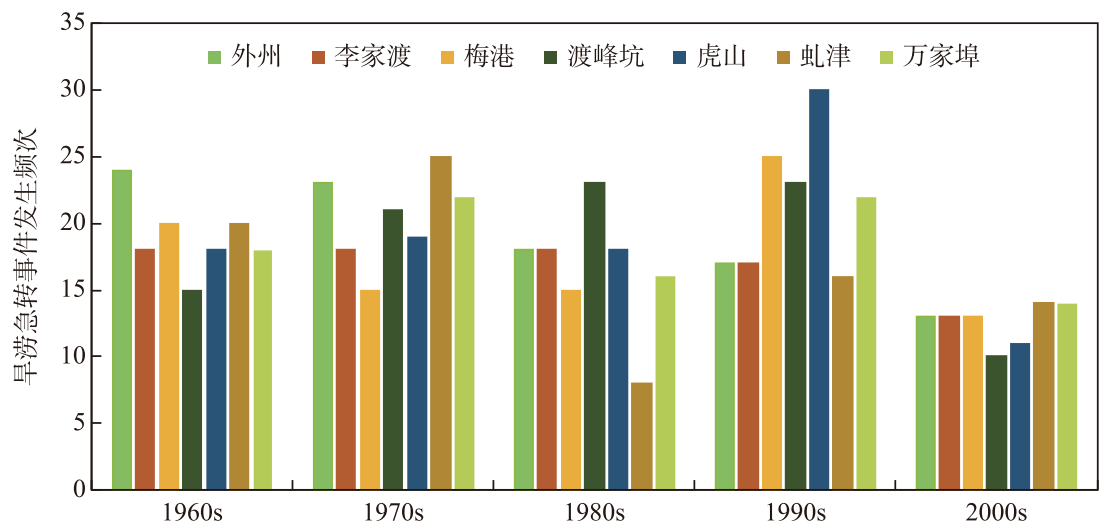

图 4 鄱阳湖流域五河 7 站旱涝急转事件发生频次的年代际变化

Fig.4 Decadal occurrence times of the drought-flood abrupt alteration events at 7 hydrological stations in Lake Poyang Basin

表 4 鄱阳湖流域五河 7 站 IMF 分量的周期特征

Tab.4 The cycle characteristics of IMFs components at 7 hydrological stations in Lake Poyang Basin

\begin{tabular}{cccc}
\hline 序号 & 径流控制站 & $I M F 1 / \mathrm{a}$ & $I M F 2 / \mathrm{a}$ \\
\hline 1 & 外州 & 1 & 35 \\
2 & 李家渡 & 1 & 26 \\
3 & 梅港 & 1 & 21 \\
4 & 渡峰坑 & 1 & 35 \\
5 & 虎山 & 1 & 21 \\
6 & 虬津 & 1 & 35 \\
7 & 万家埠 & 1 & 53 \\
\hline
\end{tabular}

同时对鄱阳湖流域五河 7 站 SDFI 年最小值和最大值序列也分别进行 EEMD 分解,得到 4 个本征函数, 但仅 $I M F 1$ 通过了显著性检验, IMF $2 、 I M F 3$ 及 $I M F 4$ 均未通过检验. 分别对各站 $I M F 1$ 进行周期和方差贡献 率分析(表 5 ). 由表 5 可知, 五河 7 站 $S D F I$ 最小值和最大值序列的 $I M F 1$ 方差贡献率在 $51.59 \% \sim 79.83 \%$ 之 间, 表明 $I M F 1$ 反映了 $S D F I$ 序列的绝大部分信息, 同时, 各站 $S D F I$ 最小值序列与最大值序列在周期变化上 具有较好的一致性,均表现为 $3 \mathrm{a}$ 左右的周期,这可能与长江流域夏季降水具有 $2 \sim 3 \mathrm{a}$ 的周期振荡有关 ${ }^{[45]}$.

表 5 鄱阳湖流域五河 7 站 $S D F I$ 最小值和最大值序列 $I M F 1$ 的周期特征

Tab.5 The cycle characteristics about minimum and maximum series of SDFI at 7 hydrological stations in Lake Poyang Basin

\begin{tabular}{ccccccc}
\hline \multirow{2}{*}{ 序号 } & 径流控制站 & \multicolumn{2}{c}{$S D F I$ 最小值 } & & \multicolumn{2}{c}{$S D F I$ 最大值 } \\
\cline { 3 - 4 } \cline { 5 - 6 } & 外州 & 周期/a & 方差贡献率 $/ \%$ & & 周期/a & 方差贡献率/\% \\
\hline 1 & 李家渡 & 2.9 & 79.83 & 2.8 & 70.02 \\
2 & 梅港 & 2.8 & 74.96 & 3.3 & 74.95 \\
3 & 渡峰坑 & 2.9 & 58.76 & 2.9 & 61.73 \\
4 & 虎山 & 2.7 & 51.59 & 3.1 & 61.27 \\
5 & 虬津 & 3.2 & 60.18 & 2.8 & 65.48 \\
6 & 万家埠 & 2.8 & 59.11 & 2.8 & 62.69 \\
7 & & & 62.46 & 2.9 & 64.31 \\
\hline
\end{tabular}


- $-S D F I$ 最小值 $\triangle-S D F I$ 最大值
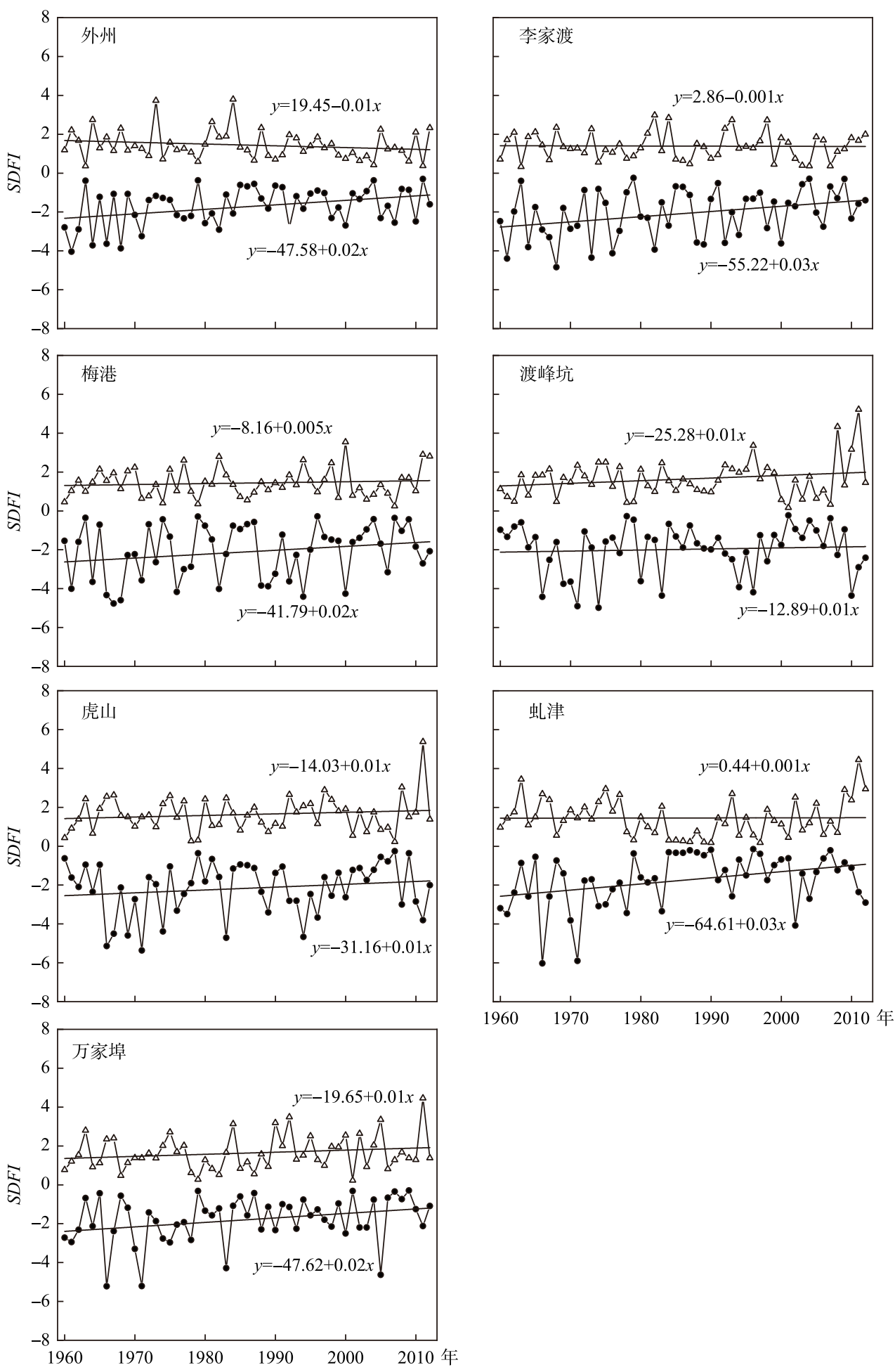

图 5 鄱阳湖流域五河 7 站 SDFI 最小值和最大值年际变化对比

Fig.5 Variations of the minimum and maximum values of SDFI at 7 hydrological stations in Lake Poyang Basin 

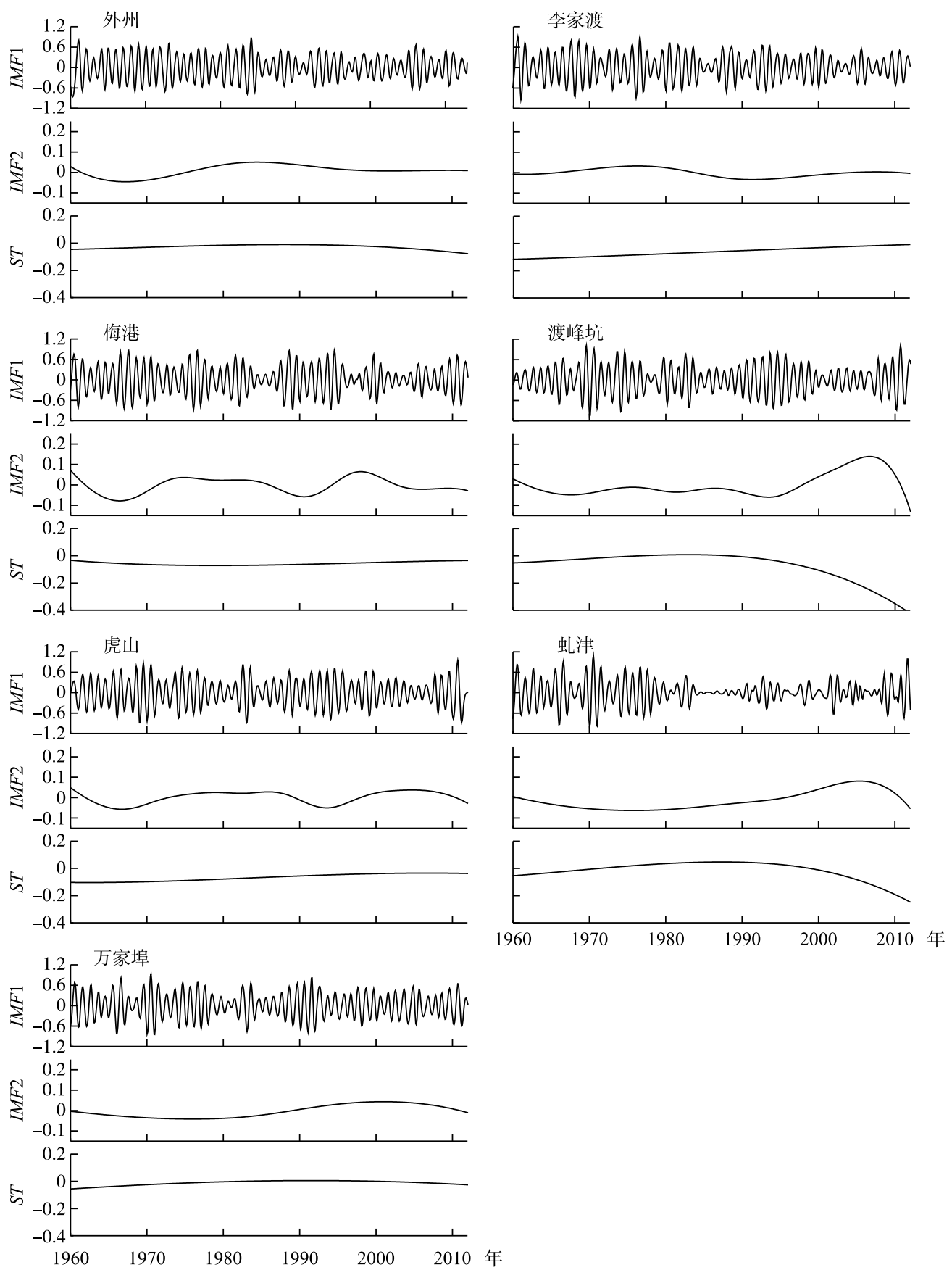

图 6 鄱阳湖流域五河 7 站 SDFI 的 EEMD 分解对比

Fig.6 EEMD decomposition results for SDFI at 7 hydrological stations in Lake Poyang Basin

\section{3 讨论}

\section{1 旱涝急转指数的不确定性分析}

旱涝急转指数已广泛运用于定量辨识旱涝急转事件, 但在实际运用中存在一定的不确定性 ${ }^{[21]}$. 其中, 
权重系数 $\alpha$ 是一个经验系数, 其取值与流域气候特征及研究的时间尺度等有关 ${ }^{[46]}$. 本文中 $\alpha$ 取值为 1.5 , 而 已有研究中也有 $\alpha$ 取值为 1.8 、2.0 及 3.2 等 ${ }^{[6,8,21]}$, 为分析不同 $\alpha$ 取值对鄱阳湖流域旱涝急转事件识别产生 的影响, 基于流域五河 7站 2000-2012 年的实测径流数据, 通过逐月径流差对 $\alpha$ 取值的不确定性进行分析. 图 7 为不同 $\alpha$ 取值下各站 SDFI 与相应的逐月径流差的相关性对比. 由图 7 可知, 当 $\alpha$ 取值 1.8 和 2.0 时,五 河各站 SDFI 与逐月径流差的确定性系数 $R^{2}$ 在 $0.67 \sim 0.94$ 间变化; 当 $\alpha$ 取值进一步增大为 3.2 时, 则各站 $R^{2}$ 明显减小, 为 $0.43 \sim 0.63$; 但当 $\alpha$ 取值减小为 1.5 时, 各站 $S D F I$ 与相应的逐月径流差的 $R^{2}$ 显著增大, 为 $0.90 \sim$ 0.96 ; 当 $\alpha$ 进一步减小为 1.3 时, 各站 $R^{2}$ 变化存在差异, 7 站中仅李家渡、虬津、万家埠站 $R^{2}$ 有所增加, 其余各 站呈不同程度的减小. 因此, 当 $\alpha$ 取值 1.5 时, 鄱阳湖流域五河 7 站的 SDFI 与相应的逐月径流差的确定性系 数达最大,其计算得到的 SDFI 更能准确地反映鄱阳湖流域五河径流的丰枯变化及旱涝急转状况.

\section{2 鄱阳湖流域旱涝急转事件成因探讨}

气候变化与人类活动是影响流域旱涝急转事件时空分布及变化趋势的重要因素 ${ }^{[21]}$. 降水作为流域径 流的主要补给源, 其年内分布直接影响径流的年内分布, 当降水年内分布不均匀、极端降水频发时, 更容易 引发旱涝急转事件 ${ }^{[19]}$. 由图 8 可知,五河的降水不均匀系数在 1960s、1990s 普遍偏高, 说明该时段内流域降 水年内分配极不均匀,如赣江在 1962 年降水不均匀系数达到最大值 1.06 , 其对应年份发生了 1 次重度 “涝 转旱” 事件和 2 次中度 “旱转涝” 事件,信江的降水不均匀系数在 1967 年达 1.14 , 其对应年份也发生 1 次重 度“涝转旱”事件, 而在 1995 年, 信江、饶河和修水流域降水不均匀系数均达到最大值, 其对应年份各自发生 1 次、3 次和 2 次旱涝急转事件. 而 1990s 旱涝急转事件多发、2000s 旱涝急转事件发生较少, 也与流域降水不 均匀系数在 2000s 表现为减小存在很好的对应关系. 因此, 鄱阳湖流域降水的年内分布不均是造成五河径流 旱涝急转事件发生的主要原因.

此外, 强烈的人类活动, 如水库建设、河流调控和大面积植树种草等对鄱阳湖流域旱涝急转事件的发生 也具有一定的影响. 据统计, 鄱阳湖流域大、中型水库数量及总库容随时间变化呈阶梯状增加 ${ }^{[47]}$. 截止到 2007 年, 鄱阳湖流域已修建各类水库近万座, 其中大中型水库 179 座, 总库容达 $113.6 \times 10^{8} \mathrm{~m}^{3[48-49]}$. 水库 “削 洪补枯” 的调控机制可有效减少洪旱灾害的可能性 ${ }^{[26,50]}$. 同时,水库调蓄能明显影响河流基流, 唐国华等选 取鄱阳湖流域 3 座大型水库定量分析水库调蓄对五河人湖基流的作用机制, 发现这 3 座水库运行使基流每 年平均增加 $89 \mathrm{~m}^{3} / \mathrm{s}^{[51]}$. 另外, 鄱阳湖流域由于过度开发, 水土流失严重, 在 1983 年, 其森林覆盖率为 $34.73 \%$, 从 1985 年开始全面实施国家水土流失重点治理工程, 森林覆盖率在 2010 年达到 $63.1 \%{ }^{[51]}$. 鄱阳湖 流域森林覆盖率增加可减少地表径流并延长汇流时间、坦化地表径流过程、增加河流基流, 使枯水期径流系 数增大, 年径流过程平坦化 ${ }^{[51]}$. 鄱阳湖流域水利工程调蓄和植被改善等能增加河道基流,使河道径流过程 平坦化, 对旱涝急转等洪旱灾害的发生具有缓解作用 ${ }^{[49,52]}$ 由此可见, 强烈的人类活动在一定程度上减小了 鄱阳湖流域旱涝急转事件的发生.

同时, 我们也应认识到, 水汽输送是形成降水的必要条件之一, 而水汽输送的强弱和路径变化是影响区 域降水强度时空差异的重要因素, 也是造成流域旱涝急转空间异质性的根本原因 ${ }^{[6,7,53]}$. 鄱阳湖流域地处东 亚季风区, 受大气环流影响更为突出, 并且区域水汽输送的强弱和路径受众多因素影响, 作用机制复杂, 本 文由于数据资料限制, 未能从水汽输送角度进一步深人揭示流域旱涝急转空间异质性, 这将是后续研究的 重点.

\section{4 结论}

基于鄱阳湖流域五河 7 站的实测径流数据, 通过旱涝急转指数, 定量识别了鄱阳湖流域旱涝急转事件, 并分析了其时空演变特征. 主要结论如下:

1) 鄱阳湖流域旱涝急转事件主要发生在 3-10 月,其中 3-6 月以“旱转涝”事件为主、7-10月以“涝 转旱” 事件为主; 在年代际上, 旱涝急转事件在 1990s 发生频率最高, 在 2000s 最低. 在空间上, 信江的旱涝急 转事件发生频次最多, 修水北支最少, 尤其是重度旱涝急转事件更易发生在抚河、信江和饶河流域, 而赣江 流域很少出现.

2) 鄱阳湖流域五河年最强“涝转旱” 事件的发生强度均呈逐渐减弱的趋势, 而年最强“旱转涝”事件的发 

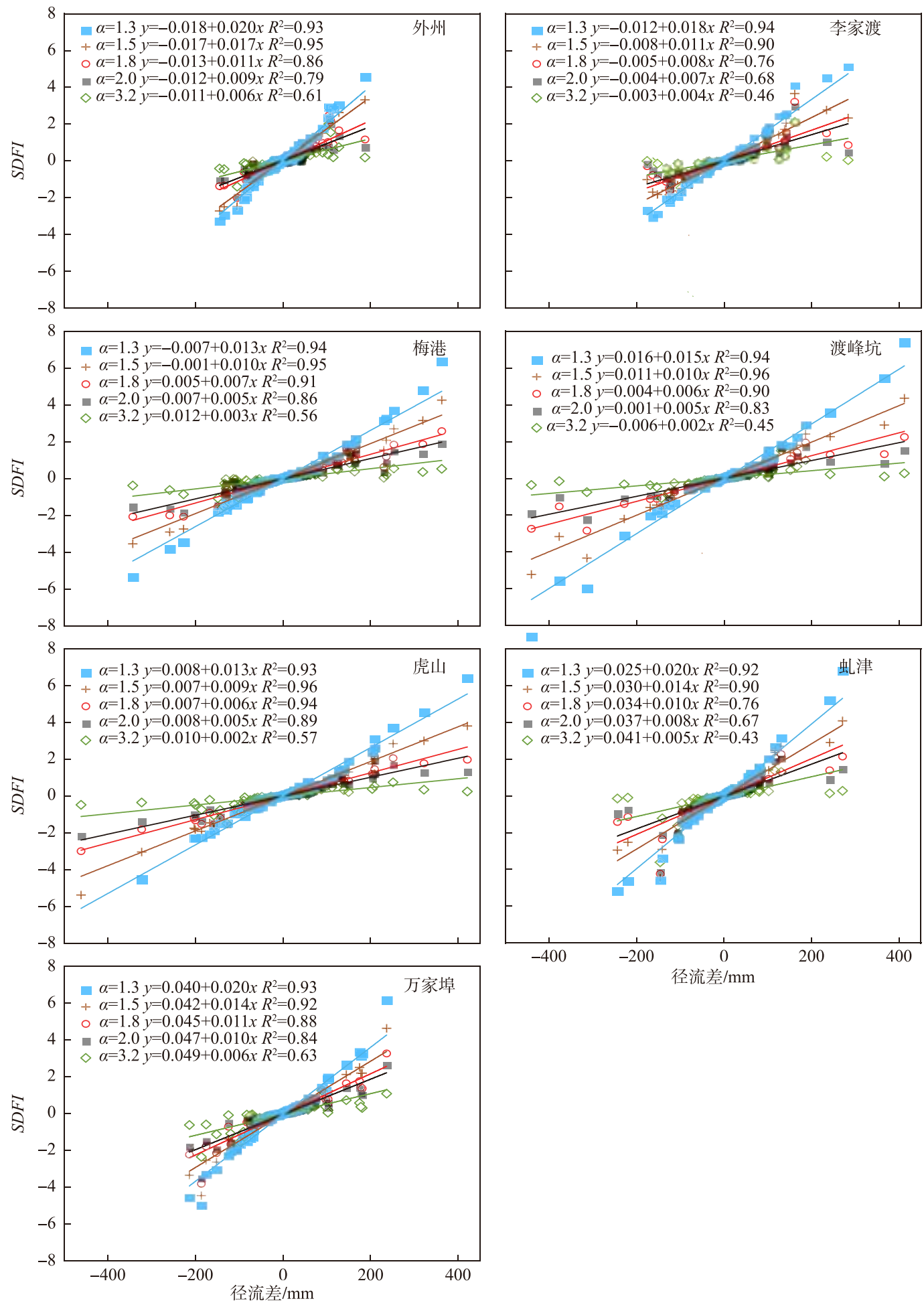

图 7 鄱阳湖流域五河 7 站不同 $\alpha$ 取值下 $S D F I$ 与逐月径流差相关性对比

Fig.7 The relationship between SDFI and the corresponding runoff difference under different $\alpha$ values at 7 hydrological stations in Lake Poyang Basin 


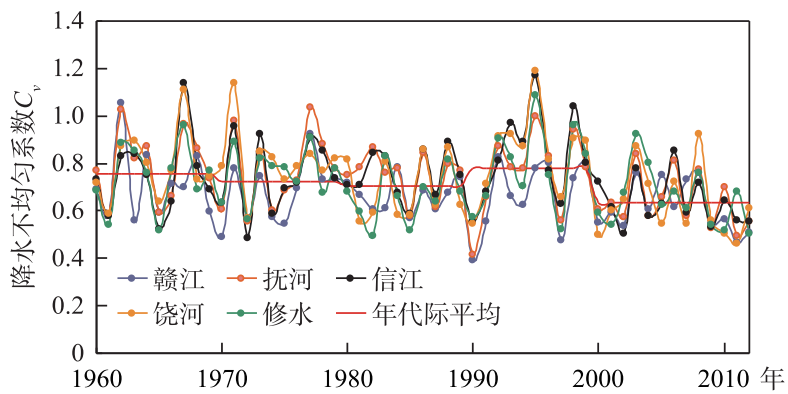

图 8 1960-2012 年鄱阳湖流域五河子流域降水不均匀系数变化

Fig.8 Variation of $C_{v}$ in five sub-catchments of Lake Poyang Basin from 1960 to 2012

生强度在贑江和修水北支有减弱趋势, 在饶河和修水南支有增强的趋势.

3) 鄱阳湖流域五河旱涝急转事件既具有高频振荡的特征, 也存在 $21 \sim 35 \mathrm{a}$ 的长周期特征, 而年最强旱 涝急转事件的发生强度则具有 $3 \mathrm{a}$ 左右的周期. 同时发现, 鄱阳湖流域降水的年内分布不均是造成五河径流 旱涝急转事件发生的主要原因, 而强烈的人类活动在一定程度上减小了鄱阳湖流域旱涝急转事件的发生 频率.

\section{5 参考文献}

[ 1 ] Zhang SF, Zhang JC, Min JJ et al. Drought-flood abrupt alternation based on runoff in the Huaihe River Basin during rainy season. J Lake Sci, 2012, 24(5) : 679-686. DOI: 10.18307/2012.0506. [张水锋, 张金池, 闵俊杰等. 基于径流 分析的淮河流域汛期旱涝急转研究. 湖泊科学, 2012, 24(5): 679-686.]

[ 2 ] Zhang LP, Du H, Xia J et al. Progress in the study of extreme hydrologic events under climate change. Progress in Geogra$p h y, 2011,30$ (11) : 1370-1379. [张利平, 杜鸿, 夏军等. 气候变化下极端水文事件的研究进展. 地理科学进展, 2011, 30(11): 1370-1379.]

[ 3 ] Wang G, Xiao WH, Lu XP et al. Advances in the research on the impact of climate change on drought and flood events. Journal of Catastrophology, 2014, 29(2) : 142-148. [王刚, 肖伟华, 路献品等. 气候变化对旱涝事件影响研究进展. 灾害学, 2014, 29(2) : 142-148.]

[ 4 ] Cheng Z, Ding XJ, Xu M et al. Climate characters of typical droughts-floods abrupt alteration events in the middle-lower reaches of the Yangtze River. Resources and Environment in the Yangtze Basin, 2012, (s2) : 115-120. [程智, 丁小俊, 徐敏等. 长江中下游地区典型旱涝急转气候特征研究. 长江流域资源与环境, 2012, (s2) : 115-120.]

[ 5 ] Huang RH, Du ZC. Evolution characteristics and trend of droughts and floods in China under the background global warning. Chinese Journal of Nature, 2010, 32(4) : 187-195. [黄荣辉, 杜振彩. 全球变暖背景下中国旱涝气候灾害的演 变特征及趋势. 自然杂志, 2010, 32(4): 187-195.]

[ 6 ] Wu ZW, Li JP, He JH et al. Large-scale atmospheric singularities and summer long-cycle droughts-floods abrupt alternation in the middle and lower reaches of the Yangtze River. Chinese Science Bulletin, 2006, 51(16) : 2027-2034. [ 吴志 伟, 李建平, 何金海等. 大尺度大气环流异常与长江中下游夏季长周期早涝急转. 科学通报, 2006, 51 (14): 1717-1724.]

[ 7 ] Feng GL, Yang HW, Zhang SX. A preliminary research on the reason of a sharp turn from drought to flood in the middle and lower reaches of the Yangtze River in late spring and early summer of 2011. Chinese Journal of Atmospheric Sciences, 2012, 36 (5) : 1009-1026. [封国林, 杨涵洧, 张世轩等. 2011 年春末夏初长江中下游地区旱涝急转成因初探. 大 气科学, 2012, 36(5): 1009-1026.]

[ 8 ] Shan LJ, Zhang LP, Zhang YJ et al. Characteristics of dry-wet abrupt alternation events in the middle and lower reaches of the Yangtze River Basin and their relationship with ENSO. Acta Geographica Sinica, 2018, 73(1): 25-40. DOI: 10. 11821/dlxb201801003. [ 内丽洁, 张利平, 张艳军等. 长江中下游流域旱涝急转事件特征分析及其与 ENSO 的关 系. 地理学报, 2018, 73(1): 25-40.] 
[ 9 ] He H, Lu H. Characteristics of the sharp turn from drought to flood over Guangxi in summer of 2013. Tropical Geography, 2014, 34(6) :767-775. [何慧，陆虹. 广西 2013 年夏季早涝急转特征. 热带地理, 2014, 34(6) : 767-775. ]

[10] Sun P, Liu CL, Zhang Q. Spatio-temporal variations of drought-flood abrupt alternation during main flood season in East River Basin. Pearl River, 2012, 33(5) : 29-34. [孙鹏, 刘春玲, 张强. 东江流域汛期旱涝急转的时空演变特征. 人 民珠江, 2012, 33(5): 29-34.]

[11] Wang S, Tian H, Ding XJ et al. Climate characteristics of precipitation and phenomenon of drought-flood abrupt alternation during main flood season in Huaihe River basin. Chinese Journal of Agrometeorology, 2009, 30(1): 31-34. [王胜, 田 红, 丁小俊等. 淮河流域主汛期降水气候特征及“旱涝急转”现象. 中国农业气象, 2009, 30(1):31-34.]

[12] Shen BZ, Zhang SX, Yang HW et al. Analysis of characteristics of a sharp turn from drought to flood in the middle and lower reaches of the Yangtze River in spring and summer in 2011. Acta Physica Sinica, 2012, 61(10) : 530-540. [沈柏 竹, 张世轩, 杨涵洧等. 2011 年春夏季长江中下游地区旱涝急转特征分析. 物理学报, 2012, 61 (10): 530-540.]

[13] Wu ZW, Li JP, He JH et al. Climate statistical characteristics of the occurrence of droughts and floods during the normal summer monsoons in South China. Progress in Natural Science, 2007, 17(12): 1665-1671. [吴志伟, 李建平, 何金海 等. 正常季风年华南夏季“旱涝并存、旱涝急转”之气候统计特征. 自然科学进展, 2007, 17(12): 1665-1671.]

[14] Tang HF, Han JG. Introduction of disastrous climate in summer, China, 1994. Disaster Reduction in China, 1994, (4): 6-8. [ 唐惠芳，韩建钢. 1994 年夏季我国灾害性天气概述. 中国减灾，1994，(4)：6-8. ]

[15] Zhang P, Fu SH, Wu ZL et al. Analysis on the sudden drought-flood alteration climate in the Huaibei City. Express Water Resources \& Hydropower Information, 2008, (S1) : 139-140. [张屏, 汪付华, 吴忠连等. 淮北市旱涝急转型气候规律 分析. 水利水电快报, 2008, (增刊) : 139-140.

[16] Yang HW. A preliminary analysis on a sharp turn from drought to flood in the middle and lower reaches of the Yangtze River in 2011 [Dissertation]. Lanzhou: Lanzhou University, 2013. [杨涵洧. 2011 年夏季中国长江中下游旱涝急转成因 分析 [学位论文]. 兰州: 兰州大学, 2013.]

[17] Cheng Z, Xu M, Luo LS et al. Climate characteristics of drought-flood abrupt change events in Huaihe river basin. Journal of China Hydrology, 2012, 32(1):73-79. [程智, 徐敏, 罗连升等. 淮河流域旱涝急转气候特征研究. 水文, 2012, 32 ( 1 ): :73-79.]

[18] Xiong W, Hu TS, Zhang BT et al. Research on the characteristics of drought and flood alternating events in sihu watershed. China Rural Water and Hydropower, 2017, (5): 155-160. [ 熊威, 胡铁松, 张兵堂等. 四湖流域旱涝交替事件 特征分析. 中国农村水利水电, 2017, (5): 155-160.]

[19] Tang M, Shao DG, Yao CL. Causes and countermeasures of sudden changing from drought to waterlogging in Huaibei region. Journal of China Institute of Water Resources and Hydropower Research, 2007, 5(1): 26-32. [唐明, 邵东国, 姚成 林. 沿淮淮北地区旱涝急转的成因及应对措施. 中国水利水电科学研究院学报, 2007, 5(1): 26-32.]

[20] Luo W, Zhang X, Deng ZM et al. Variation of the total runoff into Lake Poyang and drought-flood abrupt alternation during the past 50 years. Journal of Basic Science and Engineering, 2013, 21(5):845-856. [罗蔚, 张翔, 邓志民等. 近 50 年 鄱阳湖流域入湖总水量变化与旱涝急转规律分析. 应用基础与工程科学学报, 2013, 21(5): 845-856. ]

[21] Li X, Zhang Q, Zhang D et al. Investigation of the drought-flood abrupt alternation of streamflow in Lake Poyang catchment during the last 50 years. Hydrology Research, 2017, 48(5) : 1402-1417. DOI: 10.18307/1994.0304.

[22] Hu ZP, Ge G, Liu CL et al. Structure of Lake Poyang wetland plants ecosystem and influence of lake water level for the structure. Resources and Environment in the Yangtze Basin, 2010, 19(6): 597-605. [胡振鹏, 葛刚, 刘成林等. 鄱阳湖 湿地植物生态系统结构及湖水位对其影响研究. 长江流域资源与环境, 2010, 19(6) : 597-605.]

[23] Huang JG. Control and protection of wetland ECO-environment in Lake Poyang. Research of Soil and Water Conservation, 2007, 14(5) : 310-311. [黄金国. 鄱阳湖湿地生态环境治理及其保护. 水土保持研究, 2007, 14(5): 310-311.]

[24] Feng L, Hu C, Chen X et al. Assessment of inundation changes of Lake Poyang using MODIS observations between 2000 and 2010. Remote Sensing of Environment, 2012, 121(2) : 80-92. DOI: 10.1016/j.rse.2012.01.014.

[25] Zhang Q, Ye XC, Werner AD et al. An investigation of enhanced recessions in Lake Poyang: Comparison of Yangtze River and local catchment impacts. Journal of Hydrology, 2014, 517: 425-434. DOI: 10.1016/j.jhydrol.2014.05.051.

[26] Zhang Q, Sun P, Chen X et al. Hydrological extremes in the Lake Poyang basin, China: changing properties, causes and impacts. Hydrological Processes, 2011, 25(20): 3121-3130. DOI: 10.1002/hyp.8031.

[27] Zhang Z, Chen X, Xu CY et al. Examining the influence of river-lake interaction on the drought and water resources in the 
Lake Poyang basin. Journal of Hydrology, 2015, 522: 510-521. DOI: 10.1016/j.jhydrol.2015.01.008.

[28] Yao J, Zhang Q, Li Y et al. Hydrological evidence and causes of seasonal low water levels in a large river-lake system: Lake Poyang, China. Hydrology Research, 2016, 47(S1) : 24-39. DOI: 10.2166/nh.2016.044.

[29] Zhang Q, Sun P, Jiang T. Changing properties, causes and impacts of extreme streamflow in Lake Poyang basin, China. $J$ Lake Sci, 2011, 23(3) : 445-453. DOI: 10.18307/2011.0319. [张强, 孙鹏, 江涛. 鄱阳湖流域水文极值演变特征、 成因与影响. 湖泊科学, $2011,23(3): 445-453$.]

[30] Min Q, Zhan LS. Characteristics of low-water level changes in Lake Poyang during 1952 -2011. J Lake Sci, 2012, 24( 5) : 675-678. DOI: 10.18307/2012.0505. [ 闵骞, 占腊生. 1952-2011 年鄱阳湖枯水变化分析. 湖泊科学, 2012, 24(5): 675-678. ]

[31] Yang G, Zhang Q, Wan R et al. Lake hydrology, water quality and ecology impacts of altered river-lake interactions: advances in research on the middle Yangtze river. Hydrology Research, 2016, 47(S1) : 1-7. DOI: 10.2166/nh.2016.003.

[32] Liu J, Zhang Q, Zuo HJ et al. A surface runoff model for Lake Poyang watershed. J Lake Sci, 2009, 21(4) : 570-578. DOI: 10.18307/2009.0417. [刘健, 张奇, 左海军等. 鄱阳湖流域径流模型. 湖泊科学, 2009, 21(4): 570-578.]

[33] Li YL, Zhang Q, Li XH et al. Hydrological effects of Lake Poyang catchment in response to climate changes. Resources and Environment in the Yangtze Basin, 2013, 22(10): 1339-1347. [李云良, 张奇, 李相虎等. 鄱阳湖流域水文效应对气 候变化的响应. 长江流域资源与环境, 2013, 22(10): 1339-1347.]

[34] Ji ZH, Shan HY. Threshold diagnosis and hazard dangerousness evaluation for the disaster of drought-flood abrupt alternation in the middle and lower reaches of the Yangtze River. Resources and Environment in the Yangtze Basin, 2015,24 (10) : 1793-1798. [吉中会, 单海燕. 长江中下游地区旱涝急转的阈值诊断及危险性评估. 长江流域资源与环境, 2015, 24(10) : 1793-1798.]

[35] Lin L, Liu JT, Gan SW et al. Study on spatial-temporal variation of precipitation in western region of Taihu Lake basin based on TFPW-MK method. Water Resources and Power, 2018, 36(4) : 1-5. [林璐, 刘金涛, 甘升伟等. 基于 TFPWMK 法的太湖流域湖西区降水时空变化分析. 水电能源科学, 2018, 36(4): 1-5.]

[36] Wang YF, Chen Y, Chen XW. Runoff trend detection in the Minjiang River basin with TFPW-MK method. Science of soil and Water Conservation, 2013, 11(5) : 96-102. DOI: 10.16843/j.sswc.2013.05015. [王跃峰, 陈莹, 陈兴伟. 基于 TFPW-MK 法的闽江流域径流趋势研究. 中国水土保持科学, 2013, 11(5): 96-102.]

[37] Qian C, Yan Z, Fu C. Climatic changes in the Twenty-four Solar Terms during 1960-2008. Chinese Science Bulletin, 2011, 57(2/3) : 276-286. DOI: 10.1007/s11434-011-4724-4.

[38] Huang NE, Wu Z. A review on Hilbert-Huang transform: Method and its applications to geophysical studies. Reviews of Geophysics, 2008, 46(2) : 2007RG000228. DOI: 10.1029/2007rg000228.

[39] Wu Z, Huang NE, Wallace JM et al. On the time-varying trend in global-mean surface temperature. Climate Dynamics, $2011,37(3 / 4)$ : 759-773. DOI: 10.1007/s00382-011-1128-8.

[40] Wu Z, Schneider EK, Kirtman BP et al. The modulated annual cycle: an alternative reference frame for climate anomalies. Climate Dynamics, 2008, 31(7/8) : 823-841. DOI: 10.1007/s00382-008-0437-z.

[41] Yang YD. A method for the calculation of annual river runoff distribution. Acta Geographica Sinica, 1984,39(2): 218227. [ 杨远东. 河川径流年内分配的计算方法. 地理学报, 1984, 39(2) : 218-227.]

[42] Wang ZR, Qian YF. The multiscale characteristics of Meiyu in the Chnagjiang-Huaihe River Valley and its association with the EI Nino and the general circulation. Journal of Nanjing Institute of Meteorology, 2004, 27(3): 317-325. [王钟睿, 钱 永甫. 江淮梅雨的多尺度特征及其与厄尔尼诺和大气环流的联系. 南京气象学院学报, 2004, 27(3) : 317-325.]

[43] Bai L, Chen ZS, Zhao BF. Application of ensemble empirical mode decomposition method in multiscale analysis of Meiyu in Middle-Lower reaches of Yangtze River. Resources and Environment in the Yangtze Basin, 2015, 24(3): 482-488. [柏 玲, 陈忠升, 赵本福. 集合经验模态分解在长江中下游梅雨变化多尺度分析中的应用. 长江流域资源与环境, $2015,24(3): 482-488$. ]

[44] Wan ZW, Jia YL, Hong WJ et al. Spatiotemporal variation of drought and flood series in the Lake Poyang Basin in recent 550 years based on EEMD and EOF analysis. Resources and Environment in the Yangtze Basin, 2018, 27(4) : 919-928. [万智巍, 贾玉连, 洪炜君等. 基于 EEMD 和 EOF 的鄱阳湖流域近 550a 来旱涝时空变化. 长江流域资源与环境, 2018, 27(4): 919-928.]

[45] Huang RH, Chen JL, Huang G. The Quasi Biennial oscillation of summer monsoon rainfall in China and its cause. Chinese 
Journal of Atmospheric Sciences, 2006, 30(4) : 545-560. [黄荣辉, 陈际龙, 黄刚等. 中国东部夏季降水的准两年周 期振荡及其成因. 大气科学, 2006, 30(4) : 545-560.]

[46] Wu Z, Li J, He J et al. Occurrence of droughts and floods during the normal summer monsoons in the mid- and lower reaches of the Yangtze River. Geophysical Research Letters, 2006, 33(5) : L05813. DOI: 10.1029/2005gl024487.

[47] Luo W, Zhang X, Deng ZM et al. Runoff and sediment load transport and cause analysis in Lake Poyang basin over the period 1956-2008. Advances in Water Science, 2014, 25(5): 658-667. [罗蔚, 张翔, 邓志民等. 1956-2008 年鄱阳湖流 域水沙输移趋势及成因分析. 水科学进展, 2014, 25(5): 658-667.]

[48] Peng J. Spatial and temporal changes of runoff and sediment loads in the Lake Poyang basin since 1950 and their influence factors. Resources and Environment in the Yangtze Basin, 2015, 24(10): 1751-1761. [ 彭俊. 1950 年以来鄱阳湖流域水 沙变化规律及影响因素分析. 长江流域资源与环境, 2015, 24(10): 1751-1761.]

[49] Sun P, Zhang Q, Chen XH et al. Spatio-temporal patterns of sediment and runoff changes in the Lake Poyang Basin and underlying causes. Acta Geographica Sinica, 2010, 65(7): 828-840. [孙鹏, 张强, 陈晓宏等. 鄱阳湖流域水沙时空演 变特征及其机理. 地理学报, $2010,65(7): 828-840$.

[50] Verbunt M, Zwaaftink MG, Gurtz J. The hydrologic impact of land cover changes and hydropower stations in the Alpine Rhine basin. Ecological Modelling, 2005, 187(1) : 71-84. DOI: 10.1016/j.ecolmodel.2005.01.027.

[51] Tang GH, Xu WT, Hu ZP. Effect from forest vegetation improvement on runoff and sediment transport processes within Lake Poyang Watershed. Water Resources and Hydropower Engineering, 2017, 48(2) : 12-21. [唐国华, 许闻婷, 胡振 鹏. 森林植被改善对鄱阳湖流域径流和输沙过程的影响. 水利水电技术, 2017, 48(2): 12-21.]

[52] Ye X, Zhang Q, Liu J et al. Distinguishing the relative impacts of climate change and human activities on variation of streamflow in the Lake Poyang catchment, China. Journal of Hydrology, 2013, 494: 83-95. DOI: 10.1016/j.jhydrol.2013. 04.036 .

[53] Sun XT, Li QQ, Wang LJ. Characteristics of long-cycle abrupt drought-flood alternations in Southwest China and anomalies of atmospheric circulation in summer. Chinese Journal of Atmospheric Sciences, 2017, 14(6) : 1332-1342. [孙小婷, 李清 泉, 王黎娟. 我国西南地区夏季长周期旱涝急转及其大气环流异常. 大气科学, 2017, 14(6) : 1332-1342.] 